\title{
Acid a-galactosidase is involved in D-chiro-inositol accumulation during tartary buckwheat germination
}

\author{
Cai-Feng Jia, Wan-Hong Hu, Zhong-yi Chang, Hong-Liang Gao* \\ School of Life Sciences, East China Normal University, 500 Dongchuan Rd, Shanghai 200241, China
}

\begin{abstract}
Tartary buckwheat seed and especially its sprouts are rich in D-chiro-inositol (DCI). The research was to evaluate when DCI was most accumulated in tartary buckwheat sprouts. In addition, we explored the activity and expression pattern of a-galactosidase during tartary buckwheat seed germination. The results showed that DCI contents steadily increased at early stage of germination and reached the highest level of $33.42 \mu \mathrm{g} / \mathrm{seed}$ at $24 \mathrm{~h}$ during the $72 \mathrm{~h}$ trail. However, the total fagopyritol contents sharply decreased from $214.6 \mu \mathrm{g} / \mathrm{seed}$ to $46 \mu \mathrm{g} / \mathrm{seed}$ at the end of the germination. The activity of acid a-galactosidase increased gradually to the peak of $0.36 \mathrm{nkat} / \mathrm{seed}$ at $24 \mathrm{~h}$ after the primed seed imbibition. We cloned the gene fragment of $\alpha$-galactosidase in tartary buckwheat for the first time. The deduced amino acid sequence is $93 \%$ identical to that of $P$. vulgaris. The quantitative PCR result of gene expression pattern was consistent with its enzyme activity during seed germination.
\end{abstract}

Keywords: tartary buckwheat; D-chiro-inositol; germination; a-galactosidase; gene expression

\section{Introduction}

Tartary buckwheat (Fagopyrum tataricum) is a functional food, widely cultivated all over the world including Asia and southwest of China. As a functional food $F$. tataricum has been receiving much attention for its healing effects over chronic diseases for the long time [1]. It has been illustrated that intragastric administration of buckwheat concentrate effectively lowered serum glucose concentrations in streptozotocin-diabetic rat [2]. In humans, buckwheat has a therapeutic potential against hyperglycemia and diabetes mellitus [3].

D-chiro-inositol (DCI), a naturally occurring isomer of myo-inositol, is the main active nutritional ingredient in buckwheat. It acts as a component of a putative insulin mediator, a galactosamine D-chiro-inositol with an insulin like bioactivity [4]. DCI increase insulin sensitivity and decrease plasma glucose in obese rhesus monkeys with spontaneous insulin resistance [5]. In humans, non-insulin-dependent diabetes mellitus (NIDDM) has also been associated with decreased urinary DCI excretion [6]. Therefore, DCI has great potential to work as an adjunctive drug in the treatment of insulin resistance ailments such as type 2 diabetes and polycystic ovary syndrome [7].

\footnotetext{
* Corresponding author. Email: hlgao@bio.ecnu.edu.cn
}

Handling Editor: Grzegorz Jackowski
Buckwheat is an excellent dietary source of DCI in the form of its a-galactosides, fagopyritols, that accumulate in embryo tissues of seeds $[8,9]$. There are several form of fagopyritols accumulated in buckwheat seeds [10]. However, DCI exists as its galactosyl derivatives limits the nutritional value of buckwheat seed [8]. Previous research has demonstrated that germination may have the potential to improve the nutritional value of the grain and can effectively reduce antinutrients in cereals and legumes [11].

Seeds have a high demand for energy during early germination. Raffinose family oligosaccharides (RFOs), which are ubiquitous in plant seed and are rapidly mobilized by a-galactosidase during seed germination to provide energy [12]. RFOs are important for early germination of plant. The inhibition of raffinose oligosaccharide breakdown delayed pea seeds germination indicating that galactose is an important component during germination [13]. Uniquely, buckwheat seeds accumulate small amounts of RFOs but large amounts of fagopyritols, more than $40 \%$ percent of total soluble carbohydrates, which can be hydrolysed by the a-galactosidase in vivo, releasing galactose and the free DCI [14]. Seed priming is the technique which is commonly used to improve germination behavior and seedling emergence [15]. The application of seed priming will induce the synchronization of physiological and biochemical changes during seed germination [16].

Galactosidase can be divided into two types depending on their optimal $\mathrm{pH}$ for activity. The acidic $\alpha$-galactosidases are most likely active in the acidic environment of vacuoles 
while the alkaline forms probably catalyze galactose release in the more neutral or alkaline cytoplasm [17]. The acidic a-galactosidases prefer raffinose as the substrate in comparison with the alkaline form which shows a higher affinity for stachyose $[18,19]$. In germinating legume seeds, a-galactosidase plays a role in the mobilization of RFOs [20]. The characterization and cloning of $\alpha$-galactosidase during germination have been studied in other plant [21-23]. The activity of $\alpha$-galactosidase and the expression pattern of the gene especially during tartary buckwheat germination remain unknown.

Although some studies have been carried out to improve DCI contents in buckwheat sprouts, the effects of seed priming on DCI accumulation in tartary buckwheat sprouts have never been reported. Additionly, we cloned the gene fragment of $\alpha$-galactosidase of tartary buckwheat and further tested the gene expression during seed germination by the qPCR method.

\section{Material and methods}

\section{Tartary buckwheat seed germination}

Tartary buckwheat seeds were purchased from Sichuan province of Southwest China and stored at $-20^{\circ} \mathrm{C}$. The following germination method was adopted as we reported before [24]. The seeds were surface sterilized with $10 \%$ (v/v) of sodium hypochlorite for $3 \mathrm{~h}$ and then washed. Then the seeds were mixed with sand containing $4 \%$ (v/w) water, sealed in plastic box and primed in darkness at $15^{\circ} \mathrm{C}$ for $48 \mathrm{~h}$. After treatment, seeds were washed under tap water and dried to the original moisture content determined by weighing with forced air under shade at $27 \pm 3^{\circ} \mathrm{C}$ for 2 days. The primed seeds were spread thinly on petri dishes containing layers of wet filter paper and initiated to germinate in the dark $\left(25^{\circ} \mathrm{C}\right.$ for 72 hours). Seed samples were collected at 12 -hour intervals from 0 to 72 hours after imbibition, immediately frozen in liquid nitrogen and the samples were stored at $-80^{\circ} \mathrm{C}$ for further use.

\section{Analysis of $\mathrm{DCl}$ and total fagopyritol content}

Phenyl R-D-glucoside, trimethylsilylimidazole (TMSI) and pyridine were purchased from Sigma-Aldrich (Shanghai, China), DCI standards were purchased from Wako Pure Chemicals Industries, Ltd. (Osaka, Japan). Fagopyritol standards were extracted from seed buckwheat (Fagopyrum esculentum L.). The DCI and total fagopyritol content were performed according to the procedure of Yang and Ren [25] with slight modification. Three replications of 10 seeds each were blended for $5 \mathrm{~min}$ using homogenizer with $20 \mathrm{ml}$ of ethanol/water $(1: 1, \mathrm{v} / \mathrm{v})$ containing $10 \mathrm{mg}$ of phenyl $\mathrm{R}-\mathrm{D}$-glucoside as internal standard. The homogenate was centrifuged at $12000 \mathrm{~g}$ for $10 \mathrm{~min}$ at room temperature, supernatant was removed, and the residue was re-extracted two times with $10 \mathrm{ml}$ of ethanol/water $(1: 1, \mathrm{v} / \mathrm{v})$ for $5 \mathrm{~min}$ and recentrifuged. An aliquot of the combined extracts was filtered through $0.22 \mu \mathrm{m}$ film, transferred to silylation vials, and evaporated to dryness in a stream of nitrogen gas at $70^{\circ} \mathrm{C}$ water bath.
Extract residues were kept overnight in a desiccator over phosphorus pentaoxide to remove traces of water. Dry residues were derivatized with a silylation mixture (TMSI/ pyridine, $1: 1, \mathrm{v} / \mathrm{v}$ ) in silylation vials at $70^{\circ} \mathrm{C}$ for $30 \mathrm{~min}$, cooled, and analyzed by gas chromatograph system (GC7900, Shanghai, China) equipped with a FID detector and a HP- 5 capillary quartz column $(50 \mathrm{~m} \times 0.25 \mathrm{~mm}, 0.25 \mu \mathrm{m}$ film thickness). The initial column temperature was $150^{\circ} \mathrm{C}$, which increased gradually up to $200^{\circ} \mathrm{C}$ by the velocity of $3^{\circ} \mathrm{C} /$ min. Subsequently, it was gradually increased to $325^{\circ} \mathrm{C}$ by the velocity of $7^{\circ} \mathrm{C} / \mathrm{min}$, and then maintained for $20 \mathrm{~min}$. The inlet temperature was $335^{\circ} \mathrm{C}$ and detector temperature was $350^{\circ} \mathrm{C}$. The carrier gas nitrogen was at $1.0 \mathrm{ml} / \mathrm{min}$ (measured at $30^{\circ} \mathrm{C}$ ). The injection volume was $1 \mu \mathrm{l}$. DCI and the fagopyritols were identified by GC retention times identical to the standard.

DCI and total fagopyritols contents were quantified based on standard curves: the ratios of the area of signals for each known compound to the area of the signal for phenyl R-D-glucoside, the internal standard, were plotted against known amounts of each compound [20]. Amounts below the level of detection are presented as zero.

\section{Assay on a-galactosidase activity}

Three replications of 10 seeds each were ground in a glass homogenizer in extraction buffer $(50 \mathrm{mM}$ HEPES-NaOH, $\mathrm{pH}$ 7.4). Homogenates were centrifuged at $10000 \mathrm{~g}$ for $20 \mathrm{~min}$ at $4^{\circ} \mathrm{C}$, the supernatants were stored at $4^{\circ} \mathrm{C}$ prior to assay of $\alpha$-galactosidase activity. The enzyme activity of a-galactosidase was determined as previously described [26]. The quantitative analysis of its activity was measured by detection the p-nitrophenol released from p-nitrophenyla-D-galactopyranoside (pNPGal). The reaction mixtures consisted of $0.9 \mathrm{ml}$ substrate $(3 \mathrm{mM}$ pNPGal in $100 \mathrm{mM}$ NaAc buffer, $\mathrm{pH} 5.0$ ) and $0.1 \mathrm{ml}$ of suitably diluted enzyme preparation. The reaction was terminated by the addition of $3 \mathrm{ml}$ of $3 \% \mathrm{Na}_{2} \mathrm{CO}_{3}$ after incubation for $15 \mathrm{~min}$ at $37^{\circ} \mathrm{C}$ and the quantity of p-nitrophenol released was measured at $410 \mathrm{~nm}$. Blanks were prepared by adding the enzyme extract after $\mathrm{Na}_{2} \mathrm{CO}_{3}$. One unit of enzymatic activity, nkatal (nkat) was defined as the amount of activity that released one nmole of p-nitrophenol per second at $\mathrm{pH} 5.0$ and $37^{\circ} \mathrm{C}$. The enzyme activity was expressed in units per seed (nkat/seed). The data presented for all $\alpha$-galactosidase activity determinations are mean values of triplicate assays in which the standard deviations were always smaller than $10 \%$.

\section{Cloning and sequence analysis of FtaGAL in buckwheat}

As the buckwheat belongs to dicotyledon, the alignment of the amino acid sequence of $\alpha$-galactosidase among various dicotyledonous plant species was done with Clustal X software [27]. The conservative sequences were used for designing two degenerate PCR primers, GALF: 5'-TGGG(G/A) (A/G)T (G/A )GA(C/T)TA (C/T) T (G/A)AA(A/G)TATG-3' and GALR: 5'-TC(G/A)A(A/G)C AT (A/G) TC(G/A) GG(A/G) TC (A/G) TTCC-3'.

Seed samples were powdered in liquid nitrogen with mortar and pestle and the total RNA was extracted using Trizol reagent according to the manufacturer's instructions (Invitrogen, Carlsbad, CA, USA). Less than 500 ng RNA 
was used for the RT-PCR as specified in the RNA PCR Kit (AMV) Ver.3.0 (TaKaRa, Japan). The oligo dT-adaptor primer was used for cDNA synthesis at $42^{\circ} \mathrm{C}, 60 \mathrm{~min}$. The PCR amplification was carried out with above-described degenerate primers. The amplification profile was one cycle at $93^{\circ} \mathrm{C}$ for $3 \mathrm{~min}$, followed by 35 cycles at $93^{\circ} \mathrm{C}$ for $15 \mathrm{~s}$, $55^{\circ} \mathrm{C}$ for $30 \mathrm{~s}$ and $68^{\circ} \mathrm{C}$ for $5 \mathrm{~min}$, and a final extension step at $72^{\circ} \mathrm{C}$ for $7 \mathrm{~min}$. The amplified products were recovered from $2.0 \%$ agarose gels, cloned into the pGEM-T vector, and transformed into Escherichia coli DH5a. Sequencing was performed commercially and sequence analyses were performed using BLAST from the NCBI (http://www.ncbi. nlm.nih.gov/Tools/).

\section{The expression pattern of a-galactosidase \\ during tartary buckwheat germination}

The primers for Ft $\alpha$ GAL were designed based on the obtained cDNA sequence. The housekeeping gene $\beta$-actin was used as internal reference. The primer pairs for Ft $\alpha G A L$ were FtaGAL-F: 5'-GATACCCTCCCATGCGTGATGC-3' and FtaGA-R: 5'-GCATAGGCTGCC CACTTGTCAT-3'. The deduced amplification length was $203 \mathrm{bp}$. The primer pair for $\beta$-actin was actin-F: 5'-GCTGGATTTGCTGGAGATGATGC-3' and actin-R: 5'-CTTCTCCATGTCA TCCCAGTTGCT-3' and the deduced amplification length was $196 \mathrm{bp}$.

Total RNA and first-stand complementary cDNA of buckwheat seeds at different germination stages were prepared as described above. The internal reference gene $\beta$-actin and target gene FtaGAL were analyzed in one plate, and each reaction was repeated three times to access the reproducibility. The cycling protocol consisted of denaturation at $95^{\circ} \mathrm{C}$ for $5 \mathrm{~s}$, annealing at $58^{\circ} \mathrm{C}$ for $15 \mathrm{~s}$, elongation at $72^{\circ} \mathrm{C}$ for $20 \mathrm{~s}$, and the PCR reaction was run for 40 cycles. The fluorescence data was collected at $81^{\circ} \mathrm{C}$ for $20 \mathrm{~s}$. The model $2^{-\Delta \Delta C T}$ for comparing relative expression results between samples in real-time PCR was applied. The expression of target gene, normalized to the reference control and relative to a calibrator (time-zero sample) is given by $R=2^{-\Delta \Delta \mathrm{CT}}$, where $\Delta \Delta \mathrm{CT}=\Delta \mathrm{CT}$ sample $-\Delta \mathrm{CT}$ control. All samples were performed in triplicates. Positive and negative controls were performed on each plate.

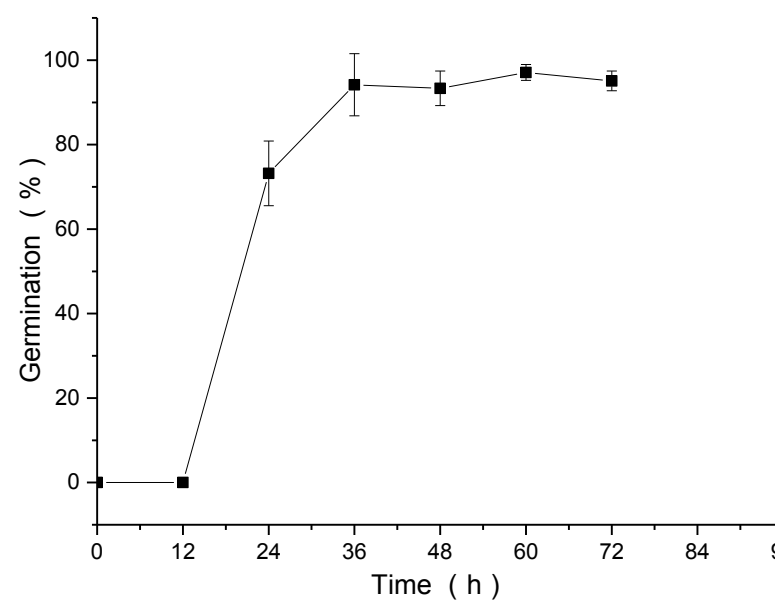

Fig. 1 Time course of germination of primed tartary buckwheat during the first $72 \mathrm{~h}$. Data presented are means $\pm S D(n=3)$.

\section{Results}

\section{Seed germination of tartary buckwheat}

Seed priming enhanced tartary buckwheat seed performance with respect to the speed and uniformity of germination (Fig. 1). The tartary buckwheat seed, after priming, began to germinate just 12 hours after incubation on wet paper layers. In the following time, seed germinated quickly and reach $73.2 \%$ at $24 \mathrm{th} \mathrm{h}$, then reached the maximum germinability as high as $94 \%$ at 36 th $\mathrm{h}$. It indicates that the fastest germination must take place between $12 \mathrm{~h}$ and $24 \mathrm{~h}$ and the complicated physiological and biochemical changes may occur in this period.

\section{The contents of $\mathrm{DCl}$ and total fagopyritol during \\ tartary buckwheat germination}

The contents of DCI and total fagopyritol in tartary buckwheat seeds were determined at different germination stages (0-72 h; Fig. 2). The DCI contents increased dramatically during the early germination. At $24 \mathrm{~h}$, it reached the maximum level of $33.4 \mu \mathrm{g} / \mathrm{seed}$, which was about 2.3 times that of time-zero seeds. However, after $24 \mathrm{~h}$, the DCI content in tartary buckwheat sprouts sharply decreased. After $60 \mathrm{~h}$, the level was lower than that of time-zero seeds. Therefore, the optimum time for tartary buckwheat germination was 24 $\mathrm{h}$, yielding the maximum DCI content. The total fagopyritol content revealed an opposite trend, decreased during the tested period from $214.6(0 \mathrm{~h})$ to $46 \mu \mathrm{g} / \mathrm{seed}(72 \mathrm{~h})$. The breakdown of fagopyritol may release $\mathrm{D}$-chiro-inositol and galactose, indicating that they may play a special role during early germination.

\section{Enzyme activity assay of a-galactosidase during the germination}

Acid a-galactosidase has great influence on seed development and germination, therefore, recent studies have paid much attention to it [28]. The activities of the alkaline a-galactosidase were very low and changed little during the buckwheat seed germination (data not shown). The activities of acidic $\alpha$-galactosidase in tartary buckwheat seeds were measured at different germinating periods (Fig. 3). The activity of $\alpha$-galactosidase exhibited high even at time-zero and increased slowly during the next $36 \mathrm{~h}$ of germination

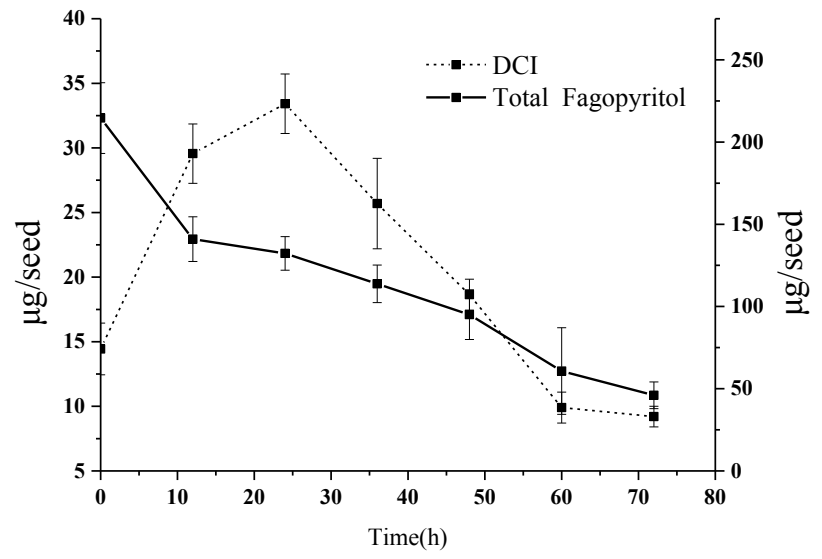

Fig. 2 Changes in DCI and total fagopyritol content of tartary buckwheat in germinating tartary buckwheat. Data presented are means $\pm S D(n=3)$. 


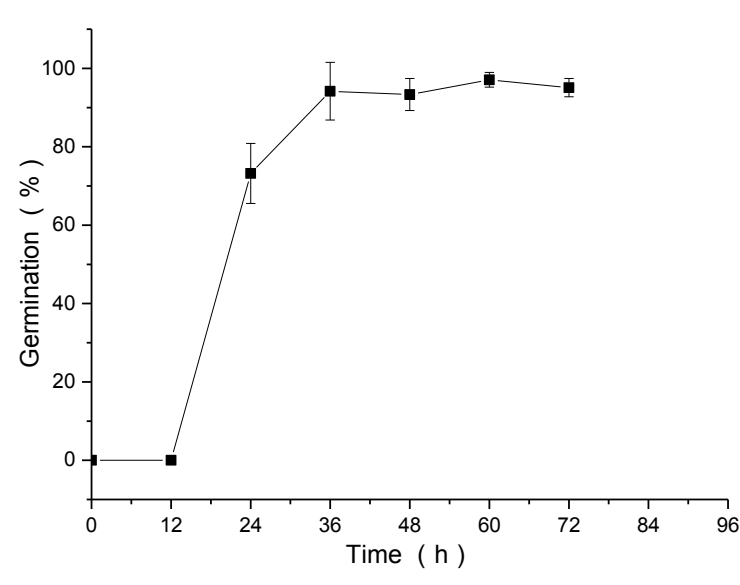

Fig. 3 a-galactosidase activity in primed tartary buckwheat seed during germination. Data presented are means $\pm S D(n=3)$.

(from 0.30 to $0.36 \mathrm{nkat} / \mathrm{seed}$ ). However, it decreased rapidly and at the end of the germination it was only 0.12 nkat/seed.

\section{Cloning and identification of FtaGAL gene}

The consecutive amino acid sequences of $\alpha$-galactosidase in dicotyledonous were aligned and the protein exhibited a highly conservative sequence (Fig. 4). The degenerate primers were used and the cloned partial cDNA of FtaGAL is 293 nucleotides. Multiple alignments revealed a high degree of homology between deduced amino acid sequence of Fta-GAL and a-Galactosidase of other plants. The highest identity was found to be $93 \%$ similarity with $P$. vulgaris. The deduced sequence covered $23 \%$ of the full length of the $P$. vulgaris a-galactosidase protein sequence. Fta-GAL showed less homology with that of Glycine max (91\%), Cicer arietinum (90\%) and Salvia mitiorrhiza (90\%).

\section{Expression of a-galactosidase gene in tartary}

\section{buckwheat seed during germination}

Quantitative PCR was used to analyze the gene expression pattern during tartary buckwheat seed germination (Fig. 5). The mRNA level of $\alpha$-galactosidase in buckwheat seeds increased steadily during early germination. At $24 \mathrm{~h}$ it reached the peak as 2.59 fold in comparison with that of time-zero seeds. Up-regulation of the genes responsible for the fagopyritol breakdown was expected, which was in accordance with the activity of a-galactosidase in tartary buckwheat seed. However the gene expression was found to be down-regulated at the later stages of germination, it declined to only 0.12 fold relative to control at the end of the germination. This correlated with the decrease of the activity of $\alpha$-galactosidase in buckwheat germination.

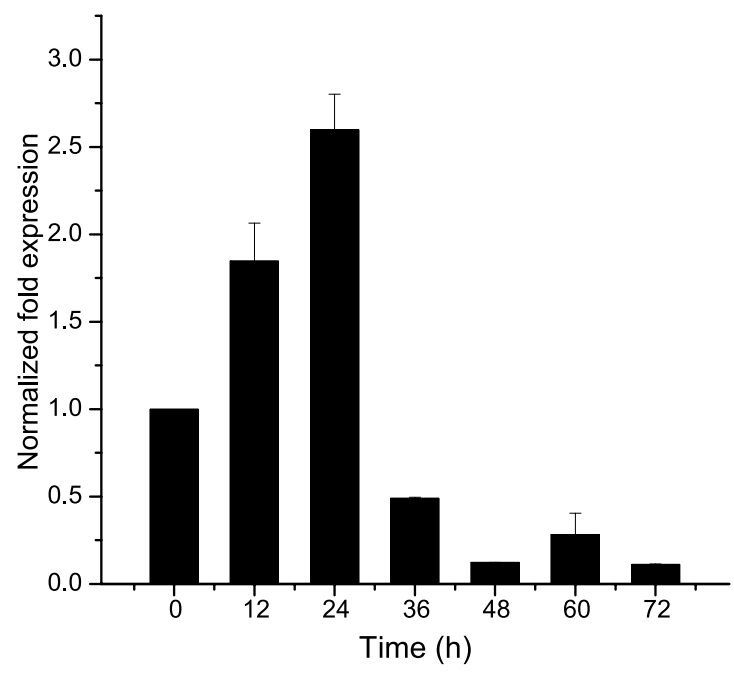

Fig. 5 Expression pattern of $\alpha$-galactosidase gene during tartary buckwheat germination. The relative expression of $\alpha$-galactosidase was quantified in comparison with the ACTIN using quantitative PCR with gene-specific primers. The values represent the average of three independent samples. Data presented are means $\pm S D(n=3)$.
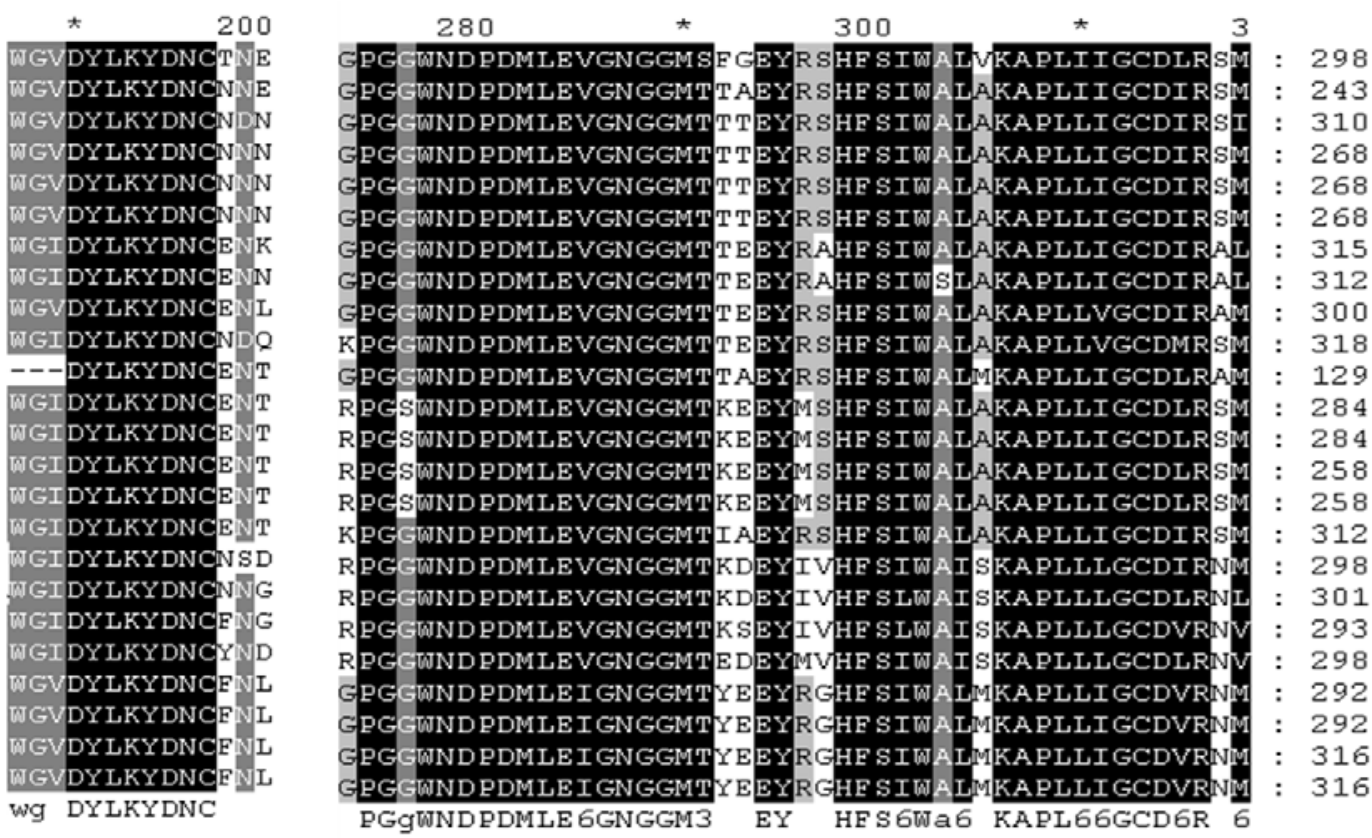

Fig. 4 The consecutive amino acid sequences of $a$-galactosidase gene in dicotyledon. 


\section{Discussion}

Buckwheat has attracted increasing attention as a potential functional food for a long time. However, the best usage of it is rarely reported. Elicitor molecules such as salicylic acid (SA) and methyl jasmonate (MeJA) have been used to induce the high yield of free DCI in buckwheat [29]. DCI was significantly higher in the metallic additives treated samples than in the control during the tartary buckwheat germination [30]. The second metabolites have been demonstrated to be accumulated in some plants, by stimulating the activity of enzymes [31]. Germination has been reported to stimulate the production of second metabolites in some cereal seeds such as buckwheat [32]. Seed priming is a promising treatment to improve the rate and uniformity of germination and is associated with increase of enzyme activity in rice seed germination [33]. The seed priming method is used to induce the high yield of DCI during the germination process in this paper and the results show that it reaches the highest level of $33.42 \mu \mathrm{g} / \mathrm{seed}$ at $24 \mathrm{~h}$ after imbibition, which provides us the optimum time to make better use of the buckwheat seed for free DCI. These phenomena may attribute to the biochemical metabolism in seed germination [34]. Similarly Zalewski et al. observed that DCI content kept increasing in the first $48 \mathrm{~h}$ of seed germination in yellow lupin [35]. In addition, Pathak also found that soaking and early germination converted soybean seeds into an effective blood sugar regulator [36].

\section{Acknowledgments}

The author acknowledges the financial support granted by University Innovation Foundation project (No. 78210259) of East China Normal University, People's Republic of China.

\section{Authors' contributions}

The following declarations about authors' contributions to the research have been made: contributed to the conducting experiments and writing the manuscript: CFJ; contributed to data acquisition: WHH; contributed to the analysis and interpretation of data: $\mathrm{ZC}$; contributed to the conception and design of this paper: HLG.

\section{Competing interests}

No competing interests have been declared.

\section{References}

1. Zhang ZL, Zhou ML, Tang Y, Li FL, Tang YX, Shao JR, et al. Bioactive compounds in functional buckwheat food. Food Res Int. 2012;49(1):389-395. http://dx.doi.org/10.1016/j.foodres.2012.07.035

2. Kawa JM, Taylor CG, Przybylski R. Buckwheat concentrate reduces serum glucose in streptozotocin-diabetic rats. J Agric Food Chem. 2003;51(25):7287-7291. http://dx.doi.org/10.1021/jf0302153

3. Zhang HW, Zhang YH, Lu MJ, Tong WJ, Cao GW. Comparison of hypertension, dyslipidaemia and hyperglycaemia between buckwheat seed-consuming and non-consuming Mongolian-Chinese populations in Inner Mongolia, China. Clin Exp Pharmacol Physiol. 2007;34(9):838844. http://dx.doi.org/10.1111/j.1440-1681.2007.04614.x

4. Larner J, Price JD, Heimark D, Smith L, Rule G, Piccariello T, et al. Isolation, structure, synthesis, and bioactivity of a novel putative insulin mediator. A galactosamine chiro-inositol pseudo-disaccharide $\mathrm{Mn}^{2+}$ chelate with insulin-like activity. J Med Chem. 2003;46(15):3283-3291. http://dx.doi.org/10.1021/jm030071j

5. Ortmeyer HK, Bodkin NL, Lilley K, Larner J, Hansen BC. Chiroinositol deficiency and insulin resistance. I. Urinary excretion rate of
Galactosidase play an important role during plant germination. The initial enzymes in RFOs catabolism are a-galactosidases, which hydrolytically remove the terminal galactose moiety of RFOs. During soybean seed germination, the content of raffinose oligosaccharides decrease substantially, while the a-galactosidase activity increases [37]. In our paper we found that the total fagopyritol content decreased while the free DCI content increased during buckwheat germination, which indicated that DCI may be released from the fagopyritol. The analysis between $\alpha$-galactosidase activities and DCI content revealed a significant positive correlation in germinated tartary buckwheat [30]. We employ the priming method in this paper and the results show that the activity of a-galactosidase exhibited high in time-zero seeds. This may be attribute to the priming treatments significantly mobilize the $\alpha$-galactosidase activity even before imbibition.

The gene of $a$-galactosidase have been cloned and analysed in tomato seed, melon fruit and coffee bean [38-40]. Feurtado et al. [38] observed that a-galactosidase gene transcription gradually increased during tomato seed germination by using real-time fluorescence quantitative PCR. In this paper we cloned the partial sequence of $\alpha$-galactosidase of tartary buckwheat and the gene expression pattern was also evaluated. The results were in close agreement with the enzyme activity of $\alpha$-galactosidase and profiles of DCI accumulation.

chiroinositol is directly associated with insulin resistance in spontaneously diabetic rhesus monkeys. Endocrinology. 1993;132(2):640-645.

6. Suzuki S, Kawasaki H, Satoh Y, Ohtomo M, Hirai M, Hirai A, et al. Urinary chiro-inositol excretion is an index marker of insulin sensitivity in Japanese type II diabetes. Diabetes Care. 1994;17(12):1465-1468. http://dx.doi.org/10.2337/diacare.17.12.1465

7. Yang N, Ren G. Application of near-infrared reflectance spectroscopy to the evaluation of rutin and D-chiro-inositol contents in tartary buckwheat. J Agric Food Chem. 2008;56(3):761-764. http://dx.doi. org/10.1021/jf072453u

8. Horbowicz M, Brenac P, Obendorf RL. Fagopyritol B1, O- $\alpha-D-$ galactopyranosyl-( $1 \rightarrow 2)$-D-chiro-inositol, a galactosyl cyclitol in maturing buckwheat seeds associated with desiccation tolerance. Planta. 1998;205(1):1-11. http://dx.doi.org/10.1007/s004250050290

9. Szczecinski P, Gryff KA, Horbowicz M, Obendorf RL. NMR investigation of the structure of fagopyritol B1 from buckwheat seeds. Bull Pol Acad Sci Chem. 1998;46:9-13.

10. Ma JM, Horbowicz M, Obendorf RL. Cyclitol galactosides in embryos of buckwheat stem-leaf-seed explants fed d-chiro-inositol, myoinositol or d-pinitol. Seed Sci Res. 2005;15(4):329-338. http://dx.doi. org/10.1079/SSR2005221

11. Luo YW, Xie WH, Jin XX, Wang Q, Zai XM. Effects of germination on iron, zinc, calcium, manganese, and copper availability from cereals and legumes. Cyta J Food. 2013;11(4):318-323. http://dx.doi.org/10 $.1080 / 19476337.2012 .757756$

12. Blochl A, Peterbauer T, Richter A. Inhibition of raffinose oligosaccharide breakdown delays germination of pea seeds. J Plant Physiol. 2007;164(8):1093-1096. http://dx.doi.org/10.1016/j.jplph.2006.10.010

13. Lahuta LB, Goszczyńska J. Inhibition of raffinose family oligosaccharides and galactosyl pinitols breakdown delays germination of winter vetch (Vicia villosa Roth.) seeds. Acta Soc Bot Pol. 2009;78(3):203-208. http://dx.doi.org/10.5586/asbp.2009.025

14. Yang N. Ren G. Determination of D-chiro-inositol in tartary buckwheat 
using high-performance liquid chromatography with an evaporative light-scattering detector. J Agric Food Chem. 2008;56(3):757-760. http://dx.doi.org/10.1021/jf0717541

15. Galhaut L, Lespinay A, Walker DJ, Bernal MP, Correal E, Lutts S. Seed priming of Trifolium repens L. improved germination and early seedling growth on heavy metal-contaminated soil. Water Air Soil Pollut. 2014;225(4):1-15. http://dx.doi.org/10.1007/s11270-014-1905-1

16. Taie HA, Abdelhamid MT, Dawood MG, Nassar RM. Pre-sowing seed treatment with proline improves some physiological, biochemical and anatomical attributes of Faba bean plants under sea water stress. J Appl Sci Res. 2013;9(4):2853-2867.

17. Daldoul S, Toumi I, Reustle GM, Krczal G, Ghorbel A, Mliki A, et al. Molecular cloning and characterisation of a cDNA encoding a putative alkaline alpha-galactosidase from grapevine (Vitis vinifera L.) that is differentially expressed under osmotic stress. Acta Physiol Plant. 2012;34(3):891-903. http://dx.doi.org/10.1007/s11738-011-0887-5

18. Gaudreault PR, Webb JA. Alkaline $\alpha$-galactosidase activity and galactose metabolism in the family Cucurbitaceae. Plant Sci. 1986;45(2):7175. http://dx.doi.org/10.1016/0168-9452(86)90039-7

19. Schaffer A, Zhifang G. Alkaline alpha-galactosidase. US 6,607,901 B1 (Google Patents) 2003.

20. Guimaraes VM, Rezende ST, Moreira MA, Barros EG, Felix CR. Characterization of alpha-galactosidases from germinating soybean seed and their use for hydrolysis of oligosaccharides. Phytochemistry. 2001;58(1):67-73. http://dx.doi.org/10.1016/S0031-9422(01)00165-0

21. Atalide GM, Borges EE, Goncalves JF, Guimaraes VM, Bicalho EM, Flores AV. Activities of a-galactosidase and polygalacturonase during hydration of Dalbergia nigra [(Vell.) Fr All. ex Benth.] seeds at different temperatures. J Seed Sci. 2013;35(1):92-98. http://dx.doi.org/10.1590/ S2317-15372013000100013

22. Schillinger JA, Dierking EC, Bilyeu KD. Soybeans having high germination rates and ultra-low raffinose and stachyose content. US 8,471,107B2 (Google Patents) 2013

23. Gajdhane S, Jadhav U, Dandge P. Biochemical study of a-galactosidase from cowpeas (Vigna unguiculata). Indian Streams Research Journal. 2014;4(1):1-5.

24. Jia CF, Zhao WC, Cai MM, Li J, Li J. Effect of sand priming treatment on seed germination of tartary buckwheat. Seed. 2011;30(1):96-98.

25. Steadman KJ, Burgoon MS, Schuster RL, Lewis BA, Edwardson SE, Obendorf RL. Fagopyritols, D-chiro-inositol, and other soluble carbohydrates in buckwheat seed milling fractions. J Agric Food Chem. 2000;48(7):2843-2847. http://dx.doi.org/10.1021/jf990709t

26. McCleary B, Matheson N. $a$-D-galactosidase activity and galactomannan and galactosylsucrose oligosaccharide depletion in germinating legume seeds. Phytochemistry. 1974;13(9):1747-1757. http://dx.doi. org/10.1016/0031-9422(74)85084-3

27. Thompson JD, Gibson TJ, Plewniak F, Jeanmougin F, Higgins DG. The CLUSTAL X windows interface: flexible strategies for multiple sequence alignment aided by quality analysis tools. Nucleic Acids Res. 1997;25(24):4876-4882. http://dx.doi.org/10.1093/nar/25.24.4876
28. Keller F, Pharr DM. Metabolism of carbohydrates in sinks and sources: galactosyl-sucrose oligosaccharides. Photoassimilate distribution in plants and crops: source-sink relationships. New York, NY: Marcel Dekker; 1996.

29. Hu, YH, Yu YT, Piao CH, LiuJM, Yu HS. Methyl jasmonate-and salicylic acid-induced d-chiro-inositol production in suspension cultures of buckwheat (Fagopyrum esculentum). Plant Cell Tiss Org. 2011;106(3):419-424. http://dx.doi.org/10.1007/s11240-011-9938-2

30. Wang L, Li XD, Niu M, Wang R, Chen ZX. Effect of additives on flavonoids, d-chiro-Inositol and trypsin inhibitor during the germination of tartary buckwheat seeds. J Cereal Sci. 2013;58(2):348-354. http:// dx.doi.org/10.1016/j.jcs.2013.07.004

31. Xu JG, Hu QP. Changes in $\gamma$-aminobutyric acid content and related enzyme activities in Jindou 25 soybean (Glycine max L.) seeds during germination. LWT - Food Sci Technol. 2014;55(1):341-346. http:// dx.doi.org/10.1016/j.lwt.2013.08.008

32. Makino Y, Soga N, Oshita S, Kawagoe Y, Tanaka A. Stimulation of $\gamma$-aminobutyric acid production in vine-ripe tomato (Lycopersicon esculentum Mill.) fruits under modified atmospheres. J Agric Food Chem. 2008;56(16):7189-7193. http://dx.doi.org/10.1021/jf801516e

33. Farooq M, Basra SM, Tabassm R, Afzal Z. Enhancing the performance of direct seeded fine rice by seed priming. Plant Prod Sci. 2006;9(4):446-456. http://dx.doi.org/10.1626/pps.9.446

34. Randhir R, Lin YT, Shetty K. Phenolics, their antioxidant and antimicrobial activity in dark germinated fenugreek sprouts in response to peptide and phytochemical elicitors. Asia Pac J Clin Nutr. 2004;13(3):295-307.

35. Zalewski K, Nitkiewicz B, Lahuta LB, Głowacka K, Socha A, Amarowicz $\mathrm{R}$. Effect of jasmonic acid-methyl ester on the composition of carbohydrates and germination of yellow lupine (Lupinus luteus L.) seeds. J Plant Physiol. 2010;167(12):967-973. http://dx.doi. org/10.1016/j.jplph.2010.01.020

36. Pathak M. Soaked and germinated soybean seeds for blood sugar control: a preliminary study. Natural Product Radiance. 2005;4:405-409.

37. Viana SF, Guimarães VM, José IC, Oliveira MG, Costa NM,Barros EG, et al. Hydrolysis of oligosaccharides in soybean flour by soybean a-galactosidase. Food Chem. 2005;93(4):665-670. http://dx.doi. org/10.1016/j.foodchem.2004.09.045

38. Feurtado JA, Banik M, Bewley JD. The cloning and characterization of a-galactosidase present during and following germination of tomato (Lycopersicon esculentum Mill.) seed. J Exp Bot. 2001;52(359):12391249. http://dx.doi.org/10.1093/jexbot/52.359.1239

39. Carmi N, Zhang G, Petreikov M, Gao Z, Eyal Y, Granot D, et al. Cloning and functional expression of alkaline $\alpha$-galactosidase from melon fruit: similarity to plant SIP proteins uncovers a novel family of plant glycosyl hydrolases. Plant J. 2003;33(1):97-106. http://dx.doi. org/10.1046/j.1365-313X.2003.01609.x

40. Zhu A, Goldstein J. Cloning and functional expression of a cDNA encoding coffee bean $\alpha$-galactosidase. Gene. 1994;140(2):227-231. http://dx.doi.org/10.1016/0378-1119(94)90548-7 